\title{
Guillain-Barre Syndrome After Minimally Invasive Transforaminal Interbody Fusion: A Case Report
}

Kingsley Abode-Iyamah ${ }^{1}$, Angela M. Bohnen ${ }^{1}$

1. Neurosurgery, Mayo Clinic, Jacksonville, USA

Corresponding author: Angela M. Bohnen, angela.bohnen@gmail.com

\begin{abstract}
Guillain-Barre syndrome (GBS) is an autoimmune disorder in which an individual's immune system attacks the peripheral nerve myelin. Although rare, but serious, the syndrome typically starts with numbness, tingling, or weakness in the lower extremities and progresses in an ascending fashion. Severe weakness can transmit into paralysis and respiratory compromise. Although rare, GBS has been reported as a complication of multiple surgeries including orthopedic, cardiovascular, transplant, and general surgeries. To our knowledge, we here present the first case report of GBS after minimally invasive transforaminal interbody fusion. Furthermore, we highlight the importance of understanding the presenting symptoms and identifying proper examination findings, particularly in the setting of confounding factors, for prompt diagnosis, treatment, and reduction of morbidity.
\end{abstract}

Categories: Internal Medicine, Neurosurgery, Rheumatology

Keywords: guillain-barre syndrome, mis tlif, gbs, ascending weakness, ascending parasthesia, ascending paralysis, transforaminal lumbar interbody fusion

\section{Introduction}

Guillain-Barre syndrome (GBS) is a rare immune-mediated disorder which often occurs following an infectious disease, affecting 0.8 to 1.9 per 100,000 persons per year [1]. Although the exact etiology remains unclear, it commonly occurs following a gastrointestinal infection with Campylobacter jejuni [2,3]. In addition, GBS has been associated with other infectious diseases such as mycoplasma pneumonia, haemophilus influenza, cytomegalovirus, Epstein-Barr virus, and post-vaccination [4-8].

Received 09/03/2019 Review began 09/20/2019 Review ended 11/20/2019 Published 11/23/2019

๑) Copyright 2019 Abode-lyamah et al. This is an open access article distributed under the terms of the Creative Commons Attribution License CC-BY 3.0., which permits unrestricted use, distribution, and reproduction in any medium, provided the original author and source are credited.
Post-insult, an autoimmune response is initiated; antibodies that attack myelin protein are produced, causing both axonal and nerve sheath damage [9]. Patients typically present with symptoms of polyneuropathy with ascending paresthesia, weakness, autonomic dysfunction and even respiratory failure $[6,7]$. Post-surgical GBS has been reported following gastrointestinal surgery, cardiac surgery, thoracic surgery, and orthopedic surgery [10]. There are few reported cases following open spinal surgery [11-16]; however, to our knowledge, there is no reported case following minimally invasive spinal transforaminal interbody fusion (MIS TLIF). Here we present a unique case of GBS following MIS TLIF.

\section{Case Presentation}

A 68-year-old woman with a history of breast cancer (prior lumpectomy and radiation), hypertension, and past surgical history of cholecystectomy, appendectomy, and right knee replacement presented with a history of back and leg pain. She referred to the emergency room due to an acute exacerbation of progressive back pain and neurogenic claudication. On examination, she had full muscle strength with some paresthesia in bilateral lower extremities. An MRI of the lumbar spine revealed grade 1 spondylolisthesis and severe canal stenosis at lumbar segment four/five (L4/5) (Figure 1). 


\section{Cureus}

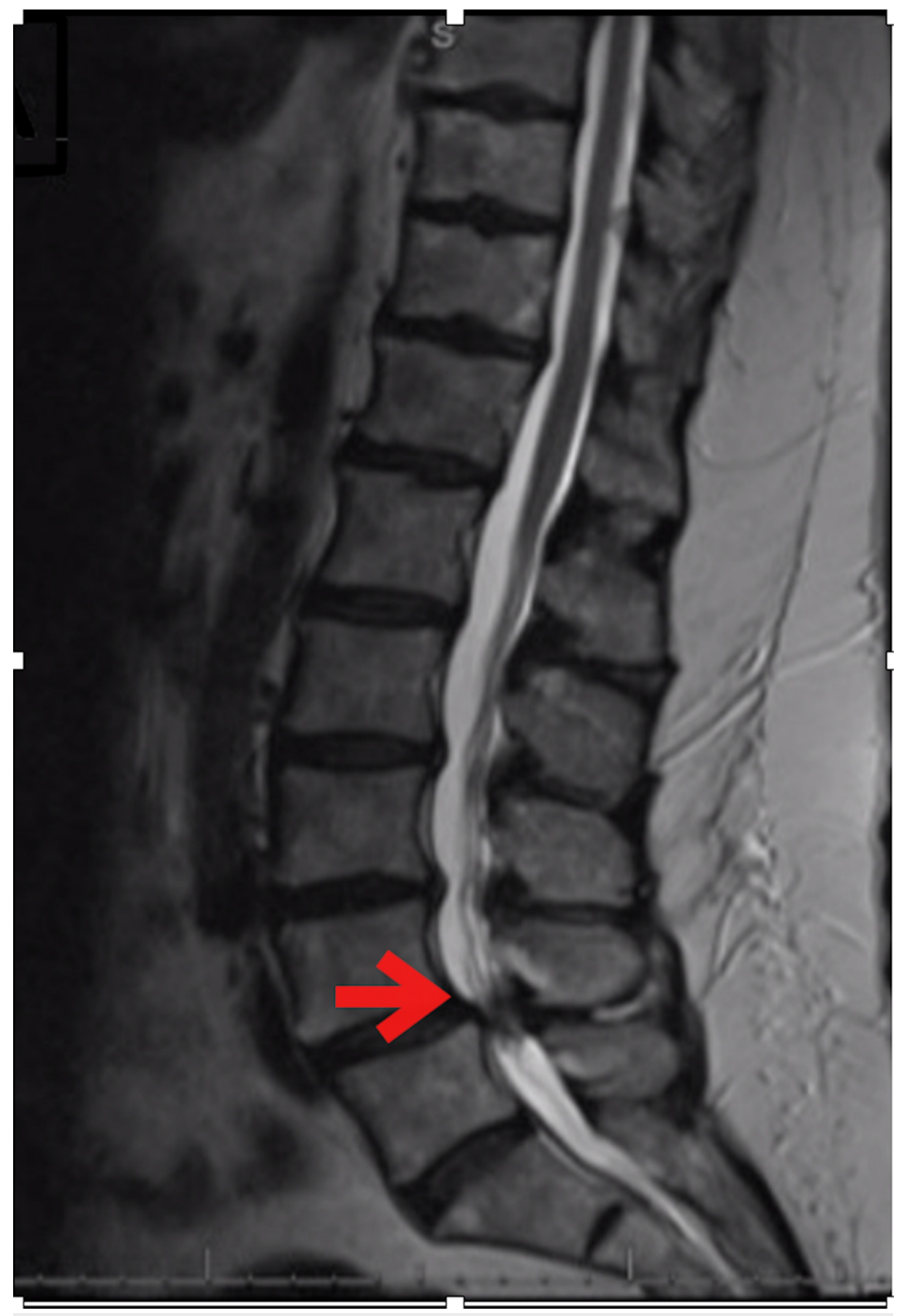

FIGURE 1: Pre-operative sagittal T2-weighted MRI demonstrating grade 1 spondylolisthesis at L4/5 with severe canal stenosis.

She underwent MIS TLIF at L4/5 with bilateral facetectomy and decompression without complication. Intraoperative somatosensory evoked potential/electromyography were uneventful. Immediately, postoperatively, the patient's paresthesias and radicular pain resolved with full motor strength. On postoperative day 5 , she reported subtle weakness $(4+/ 5)$ which progressively worsened over the 24 hours. At this time, her examination demonstrated lower extremity areflexia, numbness, and weakness in bilateral lower extremities (graded 2-3/5). The patient also reported subjective numbness in bilateral upper extremities and episodes of dyspnea; however, her respiratory rate and upper examination were normal. She denied facial symptoms.

She underwent an MRI of the entire spine which revealed a cervical 3/4 cord compression and cord signal change (Figure 2) and post-surgical decompression at the L4/5 level with instrumentation (Figure 3). The patient underwent lumbar puncture for cerebral spinal fluid (CSF) analysis, revealing protein of $257 \mathrm{mg} / \mathrm{dL}$ (high), nucleated cell count of $1 \mathrm{cell} / \mathrm{mcL}$, and red blood cell count of $24 \mathrm{cells} / \mathrm{mcL}$. Given the examination 


\section{Cureus}

and laboratory findings, she was diagnosed with GBS.

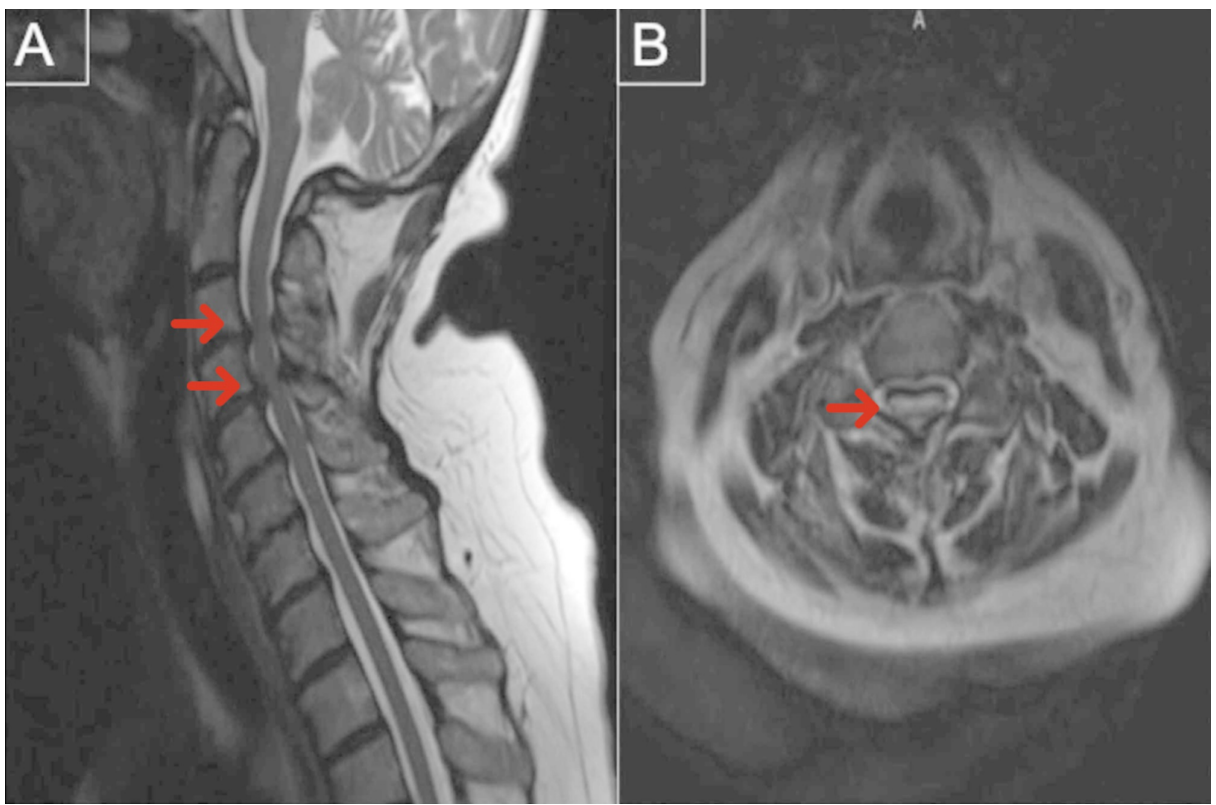

FIGURE 2: T2-weighted MRI of the sagittal (A) and axial (B) cervical spine revealing severe spinal cord compression at $\mathrm{C} 4 / 5$ with intramedullary spinal cord T2-signal. 


\section{Cureus}

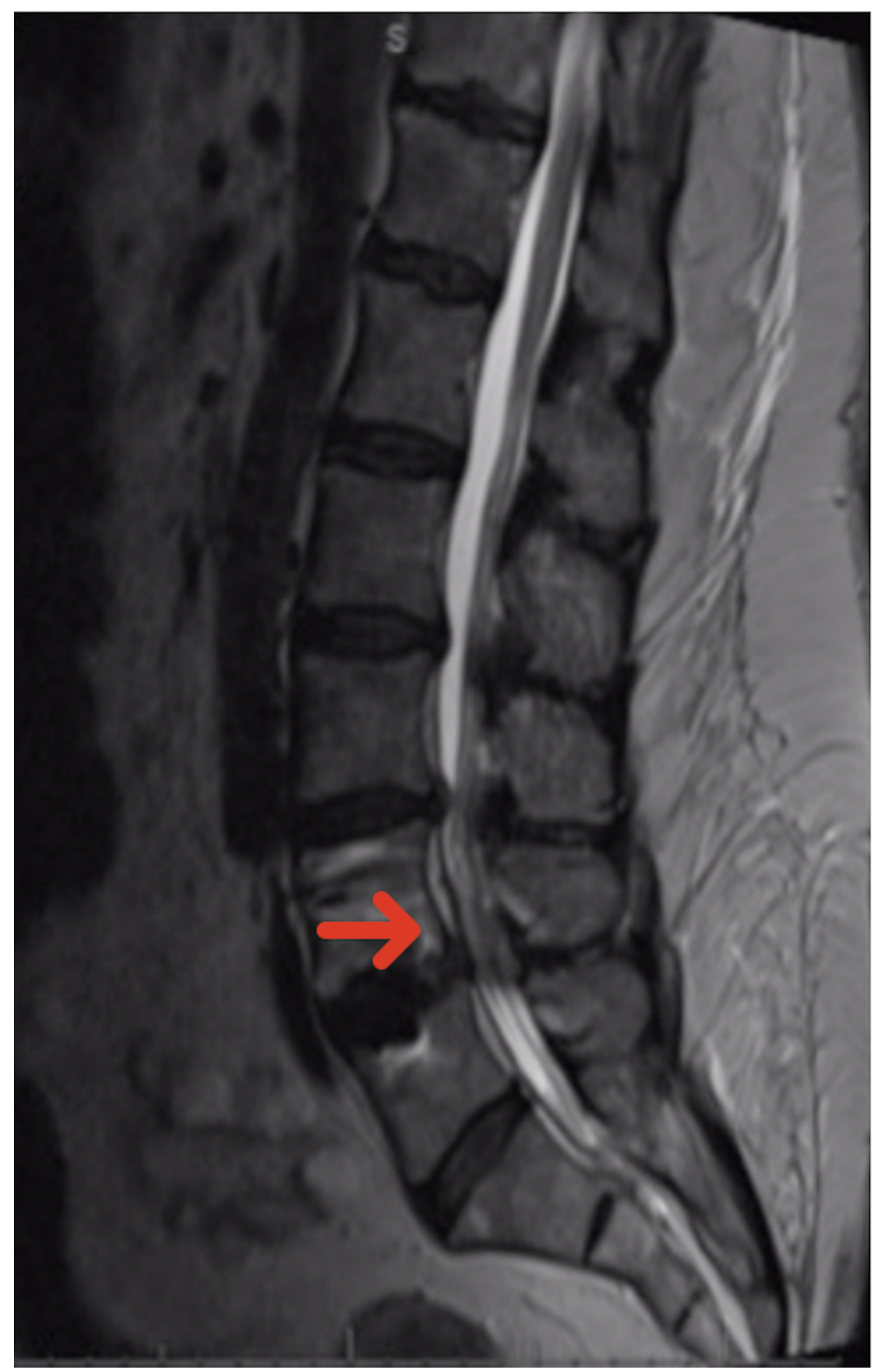

FIGURE 3: Post-operative sagittal lumbar MRI demonstrating improvement of the previous $L 4 / 5$ spondylolisthesis and canal stenosis.

The patient was treated with five sessions of plasmapheresis. She experienced some improvement of her symptoms during treatment and was eventually discharged to inpatient rehabilitation. At three months of follow-up, the patient demonstrated significant improvement; she was ambulatory with a walker, without objective leg weakness, and only slight paresthesia of bilateral lower extremities. Her pre-operative pain remained resolved. She continued to progress and at her six-month follow-up, she was ambulatory without aid and without paresthesia.

\section{Discussion}

GBS is an uncommon immune-mediated polyneuropathy whose etiology is not completely understood. It is hypothesized that it results from autoimmune antibodies and inflammatory cell cross-reactivity with 
epitomes located on peripheral nerves, leading to demyelination and axonal damage [9]. The incidence of post-surgical GBS is reported at a rate of 5\%-9.5\% although it has only been previously reported in a few cases following spinal surgery [11-16].

While there are a few reports of GBS after open spinal surgery [11-16], the current case report differs from the previously reported cases in numerous ways. First, we present a case of GBS following MIS TLIF, which has never been reported. Additionally, given the confounding factor of cervical compression, our case demonstrates the importance of careful clinical examination and history-taking in order to provide an accurate diagnosis of post-operative GBS. This patient had confounding cervical compression noted on the MRI screen post-operatively (Figure 2). While there was cord signal change, her presentation and examination did not suggest an upper motor neuron lesion. This, in addition to the ascending nature of her paresthesia and weakness, led to the proper diagnosis and haste treatment. Inaccurate, or delayed diagnosis, would have increased the potential morbidity and mortality associated with the syndrome [6]. In this case, even in the setting of cervical compression we were able to make the diagnosis by a thorough physical examination and CSF analysis.

Additionally, although recurrence of GBS only occurs in 3\% of patients, re-introducing the patient to the initiating factors may further exacerbate it $[6,7,17]$. In fact, it has been previously postulated that surgical stress activates the neuroendocrine axis and cell-mediated immunosuppression, which may play a role in promoting infections and production of cross-reactive antibodies [18,19]. The patient had undergone numerous operations previously, without event, and no known prior surgical infections. While the recurrence is low, future treating physicians will need to pay close attention to this should she require surgical intervention again. Even after resolution of the patient's symptoms, she continued to have no evidence of cervical myelopathy. We discussed close follow-up and monitoring for evidence of cervical myelopathy prior to further surgical intervention.

\section{Conclusions}

Post-surgical GBS is a rare occurrence and has never been reported following MIS TLIF. Confounding factors can exist which may complicate making the diagnosis. A thorough history, physical examination, and CSF analysis are essential for making an accurate diagnosis and providing prompt treatment.

\section{Additional Information}

\section{Disclosures}

Human subjects: Consent was obtained by all participants in this study. Conflicts of interest: In compliance with the ICMJE uniform disclosure form, all authors declare the following: Payment/services info: All authors have declared that no financial support was received from any organization for the submitted work. Financial relationships: All authors have declared that they have no financial relationships at present or within the previous three years with any organizations that might have an interest in the submitted work. Other relationships: All authors have declared that there are no other relationships or activities that could appear to have influenced the submitted work.

\section{References}

1. Sejvar JJ, Baughman AL, Wise M, Morgan OW: Population incidence of Guillain-Barre syndrome: a systematic review and meta-analysis. Neuroepidemiology. 2011, 36:123-133. 10.1159/000324710

2. Nakamura T: Infectious agents as the triggers for the pathogenesis of the neuroimmunological disorders . Nihon Rinsho. 2008, 66:1056-1064.

3. Rees JH, Soudain SE, Gregson NA, Hughes RA: Campylobacter jejuni infection and Guillain-Barre syndrome. N Engl J Med. 1995, 333:1374-1379. 10.1056/NEJM199511233332102

4. Fenichel GM: Neurological complications of immunization. Ann Neurol. 1982, 12:119-128. 10.1002/ana.410120202

5. Hemachudha T, Griffin DE, Johnson RT, Giffels JJ: Immunologic studies of patients with chronic encephalitis induced by post-exposure semple rabies vaccine. Neurology. 1988, 38:42-44. 10.1212/WNL.38.1.42

6. Hughes RA, Cornblath DR: Guillain-Barre syndrome. Lancet. 2005, 366:1653-1666. 10.1016/S01406736(05)67665-9

7. Hughes RA, Rees JH: Clinical and epidemiologic features of Guillain-Barre syndrome. J Infect Dis. 1997, 2:S92-S98. 10.1086/513793

8. Schonberger LB, Bregman DJ, Sullivan-Bolyai JZ, et al.: Guillain-Barre syndrome following vaccination in the National Influenza Immunization Program, United States, 1976-1977. Am J Epidemiol. 1979, 110:105123. 10.1093/oxfordjournals.aje.a112795

9. Levin MC, Krichavsky M, Berk J, et al.: Neuronal molecular mimicry in immune-mediated neurologic disease. Ann Neurol. 1998, 44:87-98. 10.1002/ana.410440115

10. Hocker S, Nagarajan E, Rubin M, Wijdicks EFM: Clinical factors associated with Guillain-Barre syndrome following surgery. Neurol Clin Pract. 2018, 8:201-206. 10.1212/CPJ.0000000000000451

11. Huang SL, Qi HG, Liu JJ, Huang YJ, Xiang L: A rare complication of spine surgery: Guillain-Barre syndrome . World Neurosurg. 2015, 84:697-701. 10.1016/j.wneu.2015.04.045

12. Rashid A, Kurra S, Lavelle W: Guillain-Barre syndrome after revision lumbar surgery: a case report . Cureus. 


\section{Cureus}

2017, 9:1393. 10.7759/cureus.1393

13. Chen EY, Stratton C, Mercer B, Hohler A, Tannoury TY, Tannoury C: Guillain-Barré syndrome after elective spinal surgery. J Bone Joint Surg Am. 2017, 25:587-593. 10.5435/JAAOS-D-16-00572

14. Scozzafava J, Jickling G, Jhamandas JH, Jacka MJ: Guillain-Barre syndrome following thoracic spinal cord trauma. Can J Anaesth. 2008, 55:441-446. 10.1007/s12630-009-9049-2

15. Son DW, Song GS, Sung SK, Kim SH: Guillain-Barre syndrome following spinal fusion for thoracic vertebral fracture. J Korean Neurosurg Soc. 2011, 50:464-467. 10.3340/jkns.2011.50.5.464

16. Boghani Z, Livingston AD, Simpson EP, Holman PJ, Grossman RG: Acute onset of Guillain-Barré syndrome after elective spinal surgery. World Neurosurg. 2015, 84:376-379. 10.1016/j.wneu.2015.03.036

17. Visser LH, Schmitz PI, Meulstee J, van Doorn PA, van der Meche FG: Prognostic factors of Guillain-Barre syndrome after intravenous immunoglobulin or plasma exchange. Dutch Guillain-Barre Study Group. Neurology. 1999, 53:598-604. 10.1212/WNL.53.3.598

18. Hogan BV, Peter MB, Shenoy HG, Horgan K, Hughes TA: Surgery induced immunosuppression. Surgeon. 2011, 9:38-43. 10.1016/i.surge.2010.07.011

19. Vucic S, Kiernan MC, Cornblath DR: Guillain-Barre syndrome: an update. J Clin Neurosci. 2009, 16:733-741. 10.1016/j.jocn.2008.08.033 